\title{
El nuevo documento electrónico de la tabla relacional al hiperdocumento
}

\author{
Juan Antonio Pastor Sánchez \\ Servicio de Información Universitario \\ Universidad de Murcia
}

\subsection{Resumen}

El presente trabajo realiza una crítica sobre los procesos actuales de tratamiento y gestión documental, con el objetivo de llegar a una nueva noción de documento electrónico. Para ello, aborda algunos problemas del lenguaje humano dentro del tratamiento de la información documental. Posteriormente, realiza un examen del problema de la información documental desde el punto de vista de las estructuras de conocimiento, mediante el análisis de las disfunciones en los procesos y técnicas actuales de gestión de información. El autor propone un modelo de conocimiento más cercano a la mente humana y a sus esquemas de conocimiento que denomina Hipertexto Documental. También aporta un Interfaz Conjunto de gestión de información donde se estudian aspectos tales como Hardware, Interfaces Gráficas y Metáforas de visualización de información. Se concluye afirmandoe que se está produciendo demasiada dispersión tecnológica y un tratamiento excesivamente artificial de las estructuras de información. Todo ello podría ser evitado mediante la simplificación de normas y procesos de gestión de información y la creación de interfaces integrales que acerquen los Sistemas de Información al Usuario (Autor).

Palabras clave: Estructuras de conocimiento. Documento electrónico. Gestión de informació documental. Hipertexto. Interfaz gráfica de usuario.

\subsection{Abstract}

The present work criticizes the current processes of information management, aiming with the objective of arriving to a new notion of electronic document. Some problems of the human language are approached in the frame of information management. The problem of information is examined from the point of view of the structures of knowledge, by analizing of the disfunctions in the current processes of information management. The author proposes a knowledge model nearer to the human mind and its outlines of knowledge, that it is 
called "Documentary Hipertext". A Combined Interfaces of information management also contributes where such aspects are studied as Hardware, Graphic Interfaces and Metaphors of visualization of information. Finally the author indicate that it is taking place too much technological dispersion and an excessively artificial treatment of the information structures; everything could be avoided it by means of the simplification of norms and processes of information management and the creation of integral interfaces that bring near the Information Systems to the User.

Keywords: Knowledge Structures. The Electronic Document. Informacion Management. Hipertext. Graphic User Interfaces.

\section{Reflexiones sobre el hombre y su mente}

\subsection{Información y conocimiento}

La información es un elemento vital de nuestro Cosmos. De hecho la información es el elemento constitutivo de nuestra Realidad, de un modo en el que los hechos y la materia se estructuran según unas leyes. La estructura química de cada molécula, las leyes físicas, nuestro propio cuerpo están formados por unidades informativas. Sin embargo hay que diferenciar la información (la realidad estructurada que en cierto modo es independiente del sujeto) del conocimiento (la información estructurada de la que somos consciente). Lo que no se puede estructurar o conocer mínimamente es el caos.

La información es la causa primera del conocimiento a través de una serie de procesos (percepción, análisis, evaluación), se puede considerar que el conocimiento es algo personal y subjetivo en donde influyen las vivencias y circunstacias personales del sujeto (Currás, 1995). El hombre no puede utilizar información de forma directa, sino que previamente ha debido estructurarla para obtener conocimiento.

Plantear nuestras hipótesis y actividades de trabajo desde el punto de vista del conocimiento (y no de la información) nos acerca al usuario, a la persona: lo realmente importante es proporcionar conocimiento; tratar la información a través de una serie de procesos y herramientas no pasa de ser un medio y no un fin en sí mismo.

\subsection{Hombre lingüístico $<>$ hombre alfabético}

Por regla general (siempre hay excepciones) el hombre es un ser comunicativo; siente un deseo innato de relacionarse con otros seres, con su entorno. Para realizar este proceso de comunicación se utiliza un lenguaje. El lenguaje utiliza do es indiferente, lo realmente importante es que los comunicantes lo comprendan. 
Existen multitud de lenguajes en donde la diferencia fundamental es el código y la forma en el que los conceptos se adecuan a este. Existen lenguajes por señas, símbolos, grafías, sonidos, etc. Sin embargo no hay que confundir la noción de comunicación con el de lenguaje. Asimismo hemos aprendido a una edad tan temprana la escritura alfabética que en ocasiones la identificamos con el concepto de lenguaje escrito.

La escritura fue uno de los grandes logros del hombre ya que a través de la adopción de unos criterios permite plasmar el conocimiento en un soporte y transmitirlo de un modo sencillo a través del espacio y del tiempo. Así pues a través de unos signos se representan una serie de conceptos y sus relaciones. El modelo de escritura que ha desarrollado la cultura occidental, y que más se ha extendido ha sido la escritura alfabética. De este modo a través de un conjunto reducido de grafías, se asocian combinaciones de las mismas para representar una serie de fonemas que conforman conceptos individuales relacionados entre sí a través de unas reglas sintácticas y gramaticales.

El lector debe:

- Identificar las grafías

- Unirlas para formar fonemas

- Estos fonemas conformarán una palabra, asociada a uno o varios significados

- Debe de escoger cual es el significado más adecuado

- A través de un proceso secuencial se construye la idea o hecho expresada en una frase

La enseñanza de la lectura, y sobre todo la práctica de ténicas de lectura rápida, a edades muy tempranas hace que conjuntos de signos se identifiquen directamente con uno o varios conceptos. Incluso se puede llegar a identificar frases con ideas en un solo golpe de vista. Se produce un fenómeno de alfabetización del lenguaje e incluso del pensamiento en donde hablar o pensar están mediatizados por un proceso de lectura (leer el pensamiento antes de expresarse).

La escritura alfabética (adoptada en edades tempranas) condiciona el aprendizaje de otro tipo de lenguajes matemáticos, simbólicos, musicales, etc. y en gran medida son el origen de muchos tipos de dislexias (Shaywitz, 1997)

Merecen mención aparte las escrituras ideográficas. En este tipo de escrituras una idea completa se identifica a un concepto, independientemente de su fonética. En China una misma escritura sirve para que distintos idiomas (Chino Mandarín y Chino Cantonés) se comprendan entre si. Las culturas orientales se decantaron por este tipo de escritura más sintética y donde se le concede más importancia a los conceptos y no a los sonidos. En su contra se cuenta la dificul- 
tad de dominar este tipo de escritura (con más de 5.500 símbolos para representar conceptos distintos).

\section{Tratamiento de la información documental}

\subsection{Origen del problema}

El profesional o investigador en el área de la información desarrolla sus actividades con varios problemas a sus espaldas: explosión documental, dispersión de soportes y recursos, organización y normativa heterogéneas, etc.

Hoy día se publica de todo, en cualquier lugar del mundo, con medidas de calidad muy amplias y con una difusión indefinida de la mayor parte de la producción documental. El hecho es que hoy día se documenta todo. Existen informes, patentes, normas, recomendaciones, circulares, separatas, comunicaciones, ponencias y por supuesto libros y artículos. Desgraciadamente este desmesurado desarrollo documental no se corresponde con un avance similar en las técnicas y procesos de creación de documentos, ni siquiera en las herramientas de control de estas montañas informativas (de papel por norma general).

El uso abusivo de la escritura para comunicar conocimiento es un obstáculo importante. Se intentan ajustar las ideas a las palabras perdiéndose contenido o haciéndolo ininteligible. Esto hace que la cantidad de soporte documental se incremente, independientemente se trate de papel o de un CD-ROM ya que al final, un fichero electrónico tendrá una longitud de visualización en pantalla. Por otro lado se utilizan soportes poco adecuados al carácter dinámico del conocimiento contenido en los documentos. Artículos que rápidamente quedan desfasados (investigación sobre el SIDA por ejemplo) utilizan decenas de kilos de papel. Un artículo con una extensión de 20 páginas, en una revista con una tirada de 2000 ejemplares necesitaría 20.000 folios impresos por ambos lados.

Entramos en lo que denomino laberinto del conocimiento: El autor asume aspectos tales como extensión del trabajo, referencias bibliográficas, expresión lingüística, limitación de gráficos, necesidad de curriculum o problemas de distribución de la publicación: realidades que no tienen nada que ver con el conocimiento que quiere difundir pero que al final inciden en los hábitos de trabajo del investigador y con frecuencia en la estructura y contenido del documento que publica.

\subsection{Estructuras de conocimiento}

Algunos problemas anteriormente apuntados tienen su base en las estructuras de conocimiento de nuestra sociedad. Hoy día estamos en la era de las estructuras lineales (horizontales) de conocimiento (De las Heras, 1991). El investigador, técnico o estudiante está inmerso en un entorno en donde los conocimientos se 
adquieren por acumulación. De hecho las estructuras educativas giran alrededor de un conjunto de niveles que se superan de forma sucesiva y ordenada. Para acceder a un conocimiento se tienen que asimilar previamente una serie de conceptos; esta asimilación se comprueba a través de alguna prueba. El resultado es que al hombre se le mide por la altura del conocimiento que alcanza y en muchas ocasiones se le coarta la capacidad de ampliar sus ideas de un modo más natural y flexible.

Por contra las estructuras verticales se adaptan a la propia esencia del ser humano. El hombre es un ser curioso que profundiza en aquello que más le interesa. Este tipo de esquemas permiten consultar información o aspectos de la realidad que están relacionados entre sí.

Actualmente se utiliza de forma mayoritaria el modelo relacional para la representación del conocimiento en sistemas informáticos. Este modelo parte de una normalización previa de las estructuras de datos en donde estos son atomizados y reagrupados en base a relaciones descendentes: se parte de una tabla donde se contempla la generalidad y se van analizando distintos aspectos de la realidad que representa. Por otro lado el modelo relacional es muy artificioso ya que impone una disgregación que no se da en la realidad. No se puede afirmar que el modelo relacional sea inadecuado para la representación de la realidad, sin embargo la mayoría de aplicaciones informáticas que lo utilizan obligan al usuario a interactuar de un modo excesivamente directo con estas estructuras.

El usuario se ve obligado a conocer conceptos tales como Base de Datos, Tablas, Registros, Campos, etc. En ocasiones la búsqueda y recuperación de información se hace por medio de lenguajes booleanos o del Álgebra relacional cuyo dominio se adquiere tras un proceso de formación. Esta crítica (no del modelo relacional sino del uso que se hace de él) hace necesaria una solución, en la que el usuario "dialogue" con un sistema sencillo de manejar y cuyo uso deberá resultar muy intuitivo.

Para proponer una solución ¿hay algo más sencillo que fijarse en la mente humana? Una solución de este tipo permitiría diseñar un sistema muy próximo al usuario, lo ideal sería que este tuviera la sensación de conversar con otro ser humano. Un examen superficial de nuestra mente arroja los siguientes resultados:

El hombre es "Multimedia": Somos capaces de recordar fragancias, sabores, sonidos, imágenes, conceptos, etc.

La mente humana posee una gran capacidad de almacenamiento. Nuestro cerebro tiene unos 100 billones de sinapsis neuronales (conexiones entre neuro çnas); si cada una de estas sinapsis se consideraran un bit la capacidad total sería de 11,3 Terabytes (más de 18000 CD-ROMs).

La recuperación de información se realiza de modo casi inmediato. En oca-

Scire. 2 : 2 (jul.-dic. 1996) 139-151 
siones cuando no podemos recordar algo, el proceso de recordar se queda en segundo plano. A todos nos ha pasado que cuando no se ha podido recordar algo se nos viene a la cabeza mas adelante cuando no estamos sometidos a una tensión excesiva.

El hombre no es capaz solamente de observar diversos aspectos del universo que le rodea, sino que a través de su capacidad asociativa también los relaciona entre sí para conformar una realidad lo más completa y válida posible.

Sin embargo la característica más potente de la mente humana es la posibilidad de analizar, sintetizar e inferir nuevo conocimiento. A través de procesos de razonamiento o intuición el hombre es capaz de crear nuevas ideas, herramientas, líneas de análisis, etc. Todo ello es en parte posible gracias a la capacidad asociativa que da paso a las funciones mentales humanas superiores.

El hombre utiliza sus conocimientos y experiencias no de forma directa, sino a través de una red de conceptos, cada uno de los cuales se identifica con una modelización parcial de la realidad. Sería fácil caer en la tentación de comparar la mente humana con cualquier lenguaje documental (un Tesauro por ejemplo), sin embargo esta red de conceptos es mucho más potente y sencilla al mismo tiempo que cualquiera de ellos.

El modelo de Hipertexto Documental (Pastor y Saorín, 1995) contempla estas cualidades. Se trata de un modelo de Hipertexto "completo". Algunas implementaciones de la idea de Hipertexto son parciales y muy pobres; sin ir más lejos el Web a pesar de ser la aplicación más conocida y extendida popularmente en Internet, no deja de ser una herramienta inmadura y deficiente para el almacenamiento y la recuperación de conocimiento (aunque no para su comunicación) debido a varios motivos: carencia de una red semántica, pobreza en la tipología de relaciones, utilidades de búsqueda y gestión textual muy dispersas, ausencia de elaboración documental cooperativa, inexistencia de estructuras activas de conocimiento, etc.

Por su parte, el Hipertexto Documental contempla estos aspectos en tres niveles en donde los más inferiores soportan a los superiores y donde estos definen constantemente a los inferiores.

El Hipertexto Documental (Fig.1) incide en el binomio red semántica/red de documentos: documentos y conceptos se relacionan entre sí. Asimismo establece una tipología muy amplia de relaciones apoyada por diversas utilidades de gestión y búsqueda textual; también concede importancia a la capacidad de elaboración de documentos en red de forma coordinada y su consulta a través de un interfaz sencillo y de fácil manejo. Este modelo tiene como punto culminante el Hiperdocumento, es decir, el análisis, síntesis y elaboración de conocimiento.

Con todo esto se persigue la consecución de un sistema muy próximo al usua- 


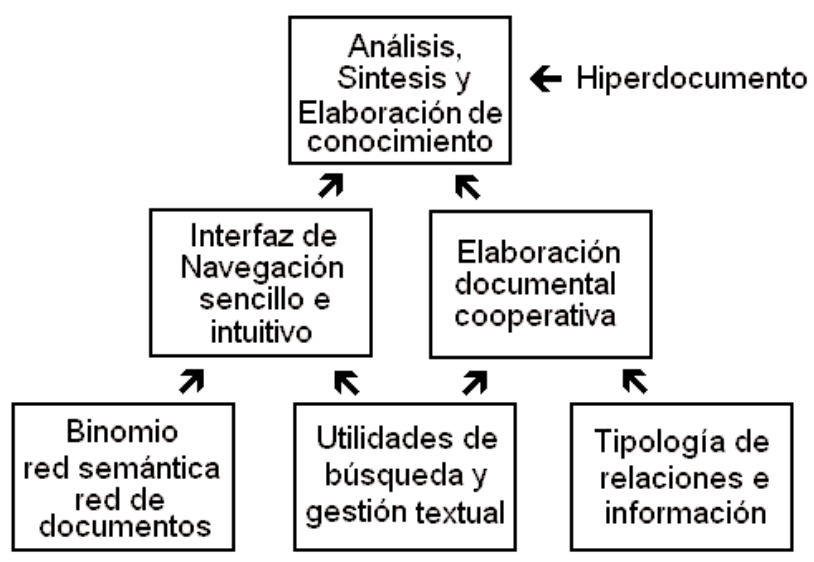

Fig. 1: Estructura del Hipertexto Documental

rio, tanto en su posibilidades como en su funcionamiento, ya que se tiene como punto de referencia la mente humana lo que favorecería la interacción entre hombre y sistema.

\subsection{Disfunciones en los planteamientos actuales}

A pesar de que a los profesionales y docentes la estructuración de las disciplinas relacionadas con la organización, almacenamiento y recuperación del conocimiento les resulte lógico y natural esto no es así para el usuario final.

Existe una gran dispersión normativa: hoy día hay normas para todo. Sin embargo se ha dado un proceso de exceso de normalización se normalizan aspectos concretos de la información documental y muy específicos. No sería descabellado pensar en la progresiva unificación de la descripción y referencia bibliográficas ya que aunque su finalidad (en un principio) es la misma analiza un mismo objeto. Además estas normas son excesivamente rígidas (colocación de signos de puntuación, separadores, formato, etc.) y a una persona no cualificada le resulta complicado consultar ciertos productos de las operaciones que son normalizadas (catálogos, bibliografías, índices)

Los lenguajes documentales y otro tipo de herramientas también carecen de una exposición sencilla y no pueden ser utilizados por el usuario sin una formación previa. En ocasiones resultan herramientas cabalísticas, con ediciones 
impresas muy extensas y demasiado estáticas. Se trabaja mucho en los lenguajes documentales y muy poco en el Lenguaje Documental. Este Lenguaje Documental debe ser muy sencillo, visual y de consulta ágil y clara. Se podría optar por la creación de un nuevo lenguaje documental o por la simplificación de los ya existentes hacia un modelo único. El ejemplo incluido en este trabajo (Fig. 2) se basa en la creación de una red de unitérminos significativos extraidos de los descriptores de un posible tesauro. Los enlaces de esta red se definen a partir de la coincidencia de los unitérminos en un descriptor

Por otro lado asistimos a una serie de carencias en la unificación de criterios para la indización y resumen. La Indización es una labor propia del documentalista que debe caracterizar el conocimiento según una serie de herramientas o lenguajes documentales; sin embargo no hay acuerdo en cuanto a la profundidad, extensión y lenguajes a utilizar, abordándose aspectos formales y no de contenido. El resumen "ideal" debería ser realizado por el autor ¿quien mejor que este para sintetizar el conocimiento que ha elaborado? Pero desgraciadamente la técnica del resumen es algo que no suele formar parte de la formación de los autores ni lo exigen todos los canales de comunicación del conocimiento (revistas científicas, editores, etc.) Ya no hablo de la posibilidad de identificar una serie de criterios para la redacción del resumen, algo tan complejo que puede llegar a convertirse en un esfuerzo que algunos podrían considerar pretencioso.

\section{Información al estudiante Becas para Estudiantes Becas para Investigación Grupos de Investigación Información Académica Titulaciones Académicas}

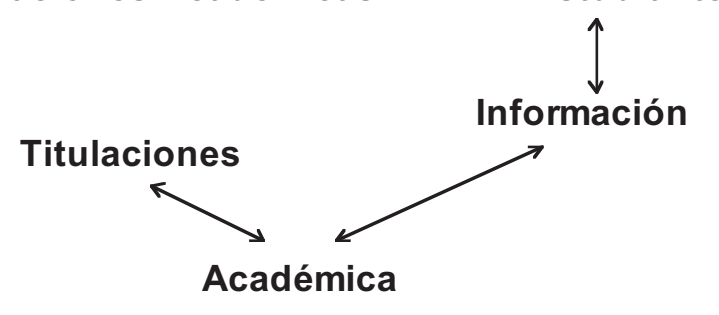

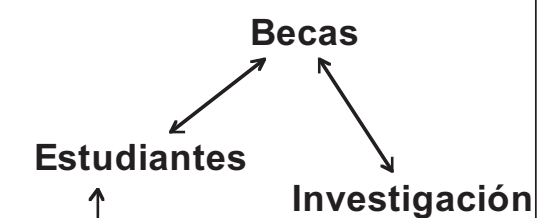

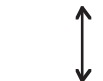

Grupos

Fig. 2: Presentación Simplificada de Términos de un Tesauro 


\subsection{El nuevo documento electrónico}

Llegados a este punto el lector podría preguntarse "pero... ¿y el nuevo documento electrónico?, ¿que tiene que ver con todo lo anterior?". Yo diría que bastante. Actualmente se ha llegado a un nuevo concepto a través de las tecnologías de la información: el documento electrónico. El ordenador y las aplicaciones (sistemas informáticos) se han convertido en un eje fundamental en torno al cual giran muchas de las espectativas respecto a los procesos de almacenamiento, recuperación y difusión del conocimiento (y en ocasiones la elaboración de éste). Pero este punto de vista se basa en el uso de la tecnología con el único fin de cambiar de soporte (pasar del papel al formato digital).

El documento electrónico, considerado como aquel documento consultable a través de un sistema informático tiene una serie de limitaciones y grandes ventajas. El documento electrónico está en una fase de ceguera tecnológica, prácticamente se ha pasado de la nada al todo de tal manera que la mayoría de los usuarios y profesionales consideran al documento electrónico como una herramienta que permitirá disponer de grandes cantidades de información multimedia.

A mi parecer se dan una serie de características que deben definir el documento electrónico:

- La unificación de distintas tipologías de información (texto, imágen, sonido) en un mismo documento (multimedia) es importante pero no fundamental

- El uso de sistemas informaticos permite la estructuración distribuida (y no lineal) del conocimiento: Hipertexto

- Las estructuras de documentos electrónicos no deben limitarse a ser recorridas por el usuario (estructuras pasivas), sino que deben interactuar con este, averiguar sus necesidades, formas de trabajo y sintetizar, caracterizar o elaborar conocimiento (Hiperdocumento)

- La unificación y la naturalidad normativa en la elaboración de documentos electrónicos facilitarán la tarea del autor de los mismos.

- El usuario debe acceder al documento electrónico de un modo sencillo y directo (sin intermediarios), lo cual se consigue a través de sistemas informáticos cuyo manejo resulta muy intuitivo y rápido. 


\section{El interfaz intuitivo: información para los sentidos}

\subsection{Niveles del interfaz conjunto}

Hasta ahora se ha hablado de sistemas informáticos sencillos e intuitivos en su manejo, en una palabra amigables. El dialogo entre hombre y ordenador ha pasado de la ficha perforada y el teclado al ratón y al micrófono, del teleimpresor a la pantalla de gran resolución, de los sistemas operativos de líneas de comandos a los interfaces con ventanas, iconos y botones.

Cuando hablamos de interfaces nos viene a la memoria entornos del tipo Windows o Mac, sin embargo hay que considerar al interfaz como una estructura en donde se unen Hardware Funcional, Aplicaciones e Interfaces Gráficos de Usuario (IGU).

El Hardware funcional (Hardware + Sistema Operativo) forma parte del interfaz: el usuario va a interactuar físicamente con el ordenador. La arquitectura que se ha impuesto hoy día es el PC. Este tipo de ordenadores resultan inadecuados para el usuario medio ya que presenta ciertas dificultades:

Ofrece múltiples tecnologías de almacenamiento de un modo no estructurado (discos duro, discos flexibles, CD-ROM, unidad ZIP, disco duro removible, magneto-óptico).

El usuario sufre problemas de localización de datos debido a que los "nuevos" soportes se quedan constantemente pequeños, además el control del contenido de estos soportes debe realizarlo el usuario (algo costoso y pesado) y no es controlado de forma automática por el propio sistema operativo.

La gestión de los equipos y la ampliación de los mismos. El cableado y el cambio de las tarjetas provoca a muchas personas un pánico a la electrocución. Se debería conseguir un Hardware en el cual actualizar una tarjeta de video sea algo tan sencillo con extraer o introducir un disco flexible.

Las aplicaciones que se comercializan actualmente son faraónicas respecto al espacio necesario en disco duro, o el equipo necesario de instalación. Hace unos años se recomendaba un PC con un procesador 80286, 2 MBs de RAM y unas 10 MBs de espacio libre en el disco duro. Hoy día la mayoría de aplicaciones requieren un equipo con 80486, 8 MBs de RAM y 40 MBs libres en el disco duro.

El modelo relacional aflora en el IGU de muchas aplicaciones de tal modo que para recuperar un determinado documento hay que construir una ecuación de búsqueda o seleccionar criterios a partir de tablas y campos. Esto hace que el manejo de los sistemas informáticos de gestión de información sea complicado a pesar de que estos sean cada vez más abiertos y amoldables al usuario.

En cuando a los IGU simplemente indicar que aunque existe un consenso implícito en el acceso a las funcionalidades de las diversas aplicaciones, segui- 
mos en el reinado del ratón y el teclado. Dos dispositivos que utilizan nuestras manos (esta frase tiene doble sentido) y cuyo uso supone un esfuerzo para muchos usuarios. Aún no se han desarrollado interfaces totalmente basados en la voz, control visual, realidad virtual (Rao, 1996), e incluso señales neuronales (Lusted y Knapp 1996).

\subsection{El interfaz como metáfora}

Es algo obvio que la metáfora con lo cotidiano es un buen método para el desarrollo de interfaces, ya que el reconocimiento de una serie de realidades por parte del usuario pueden hacer su trabajo más agradable, llevándolo a cabo de un modo más natural. Además, la creación de un IGU lo más visual posible permite un uso intuitivo de los objetos.

Es importante resaltar que trabajos realizados en el Xerox PARC (Palo Alto

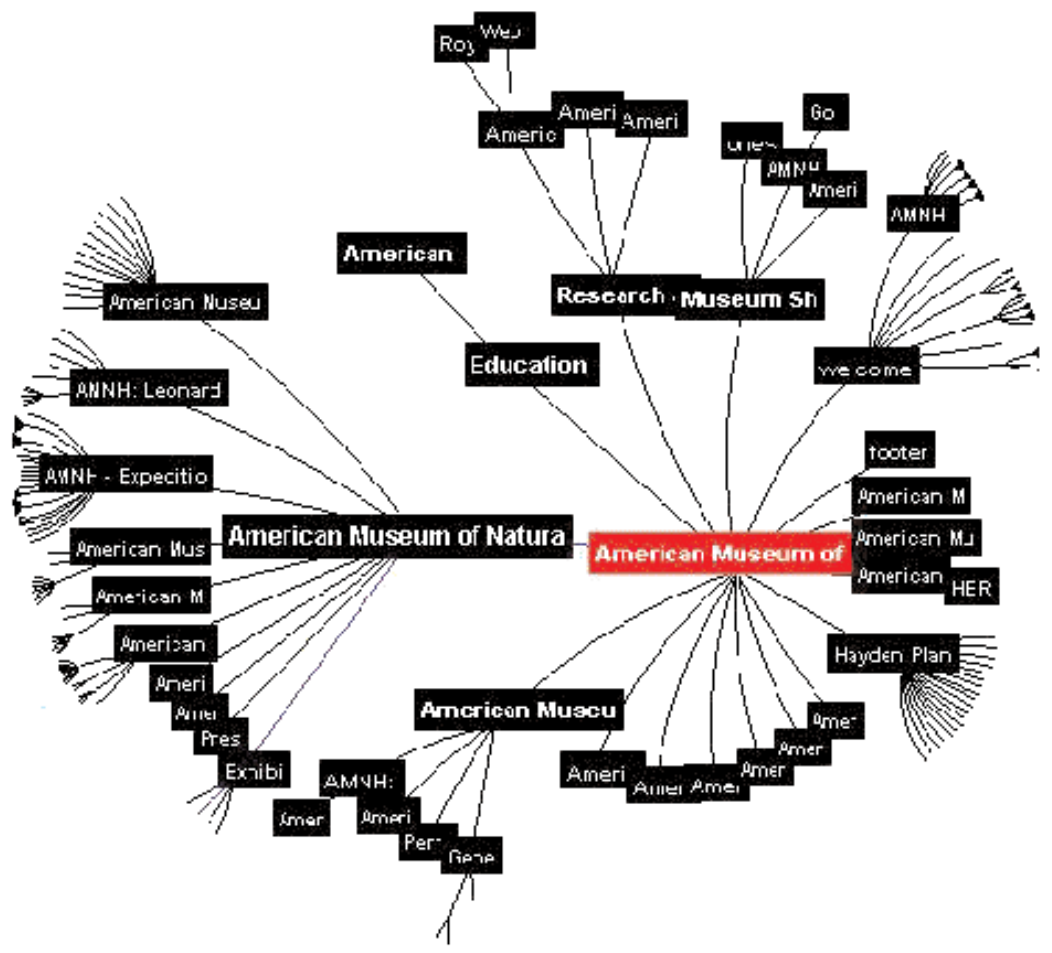

Fig. 3. El Navegante hiperbólico presenta así la estructura jerárquica de las relaciones de las páginas deL Museo Americano de Historiaen el World Wide Web. Recurre a una técnica llamada "detalle+contexto" 
Research Center) han dado origen a un nuevo concepto en la relación hombremáquina, llamado visualización de la información, que consiste en representar de forma visual e interactiva enormes cantidades de conocimiento (Rao, 1996).

Aspectos como la animación (que inciden en la capacidad de la visión humana para unir una serie de imágenes y preservar la sensación de persistencia de los objetos), manipulación de imágenes (rotación, cambios de perspectiva) o la integración de sonidos y música pueden llegar a constituir el camino que se siga en el futuro para la creación de interfaces, un futuro en donde la imaginación y el Arte tienen tanto que decir como la investigación y la tecnología.

\section{Conclusiones: ¿hacia dónde vamos? ¿hacia dónde deberiamos ir?}

Lamentablemente nos encontramos con un presente que augura un futuro poco esperanzador para el documento electrónico. Se seguirán elaborando documentos multimedia sin ningún tipo de metodología unificada lo cual se agravará por el volumen creciente de información carente de autocontrol por parte de los autores.

Las tan traídas y llevadas Redes de Información poco a poco están atrapando al usuario y empiezan a ser de escaso valor para la estructuración de la información. Se tiene la sensación de que Internet se rige a través de la Teoría matemática del Caos, y no por la coordinación de esfuerzos y la organización de recursos. Para empeorar las cosas estamos asistiendo a una Dispersión de Tecnológia, Sistemas Informáticos, Lenguajes Documentales, Normativa, Aplicaciones, etc.

Esta visión podría tacharse de pesimista si no se aportaran una serie de soluciones a estos problemas. Para empezar sería conveniente (por no decir necesario) igualar la valoración que se tiene de lenguajes visuales o sonoros con el lenguaje escrito para obtener documentos más cercanos al ser humano y que permitan una comprensión más eficaz y rápida.

Unificar y simplificar la normativa de los distintos procesos de gestión de información documental, las herramientas de acceso a la información y la creación de nuevos interfaces integrales permitiría acercar los Sistemas de Información al Usuario, con lo cual se llevaría a cabo un paso importante para esbozar la Sociedad de la Información que aún no hemos desarrollado plenamente.

\section{Referencias}

Currás, E. (1995). Concierto y desconcierto en la organización del conocimiento actual y su intersección con el mundo de la información. // SCIRE. 1 : 1 (Ene-Jun 1995) 3-28

Damasio, A.R. ; Damasio, H. (1992) El cerebro y el lenguaje. // Investigación y Ciencia. 
194 (Nov 1992) 58-66

De las Heras, A. (1991). Navegar por la Información. Madrid : Fundesco, 1991

Fischbach, G. D. (1992). Mente y Cerebro. // Investigación y Ciencia. 194 (Nov 1992) 615

Halfhill, T.; Pountain, D.; Joch, A. (1996). Dossier: Nuevos Interfaces. // Byte. 147 (JulAgo. 1996) 134-148

Lusted, H.S.; Knapp, R.B. (1996). Control de ordenadores por señales neurales. // Investigación y Ciencia. 243 (Dic. 1996) 40-45

Pastor Sánchez, J.A.; Saorín Pérez, T. (1995). El hipertexto documental como solución a la crisis conceptual del hipertexto. El reto de los documentos cooperativos en redes.// Cuadernos de Documentación Multimedia. 4 (1995) 41-56

Rao, R. (1996). Cuando la Información Salta a la vista. // Mundo Científico. 168 (May 1996) 452-459

Shaywitz, S.E. (1997). Dislexia. // Investigación y Ciencia. 244 (Ene. 1997) 68-75 